\title{
USO DE GEOTECNOLOGIAS PARA MAPEAMENTO DE ÁREAS INUNDÁVEIS EM ZONAS URBANAS: ESTUDO DE CASO DA ZONA URBANA DE PELOTAS/RS
}

\author{
USE OF GEOTECHNOLOGIES FOR MAPPING OF SUBJECT TO FLOODING AREAS IN \\ URBAN ZONES: CASE STUDY OF THE URBAN ZONE OF PELOTAS/RS
}

\section{SILVA, Cláudio Santos da}

Arquiteto e Urbanista, Mestrando do Programa de Pós-Graduação em Arquitetura e Urbanismo da UFSC. Florianópolis/SC. E-mail: cssilva@arq.ufsc.br

\section{AFONSO, Sonia}

Arquiteta e Urbanista, Dra. Faculdade de Arquitetura e Urbanismo - USP. Professora do Departamento de Arquitetura e Orientadora do Programa de Pós-Graduação em Projeto e Tecnologia do Ambiente Construído/UFSC. Florianópolis/SC. E-mail: soniaa@arq.ufsc.br

Programa de Pós-Graduação em Arquitetura e Urbanismo • PósARQ/CTC/UFSC • C.P. 476 • CEP 88040 900•Florianópolis/SC・Fone/Fax: (48) 3331-9797. E-mail: posarq@ctc.ufsc.br

\section{RESUMO}

Este trabalho tem como objeto de estudo a zona urbana do município de Pelotas-RS. Realiza a organização de dados referentes ao relevo natural do município relacionando-os com a drenagem urbana, a fim de identificar áreas de risco internas ao perímetro urbano suscetíveis a inundações. Visa, com isso, minimizar a carência de informações referentes ao tema e subsidiar a construção de um instrumento orientador para uso e ocupação do solo, além de utilidades educativas. Por meio de recursos de sensoriamento remoto e geoprocessamento foram identificadas as áreas de risco, constituindo importante instrumento para definição de áreas de expansão urbana, localização de equipamentos e atividades polventes. Os resultados apresentados com recursos de simulação digital verificam que aproximadamente $37,5 \%$ do território urbano encontra-se em cotas abaixo de 5 metros e próximos a cursos d'água, oferecendo risco de inundação. Isso vem demonstrar a relevância de diagnósticos mais aprofundados sobre drenagem urbana instrumentalizando melhor as atividades de planejamento de uso e ocupação do solo. A utilização prática do método de identificação e mapeamento demonstra a sua aplicabilidade a outros municípios.

Palavras-chave: Geotecnologias, mapeamento de áreas inundáveis, planejamento urbano.

\begin{abstract}
The subject of this work is the study of the urban zone of Pelotas City, RS, Brazil. In order to reach it, the information about the natural relief of the city area was organized and related to the urban drainage information, to identify inward risk areas, susceptible to inundation. The purpose is to minimize the lack of information related to the subject, intending to promote the composition of an orientation system to the use and occupation of the land, besides the educational aspect. Trough the resources of remote sensing environment and Geographic Position System it was possible to identify the risk, compose a important instrument to define the urban expansion areas, equipment localization and pollution activities. From the results, obtained by digital simulation, it was possible to find out that approximately 37,5\% of the urban territory are less than 5 meters high and situated near water, increasing the risk of inundation. It demonstrates the necessity of more accurate diagnosis of draining, related to the land use and occupation planning activities. The practical use of this method, identifying and mapping inundation risk areas, gives evidence of its applicability to other cities.
\end{abstract}

Key words: Geotechnologies, mapping of flooding areas, urban planning. 


\section{Introdução}

Um problema comum, identificado em grande parte dos municípios brasileiros, refere-se à falta de informações sistematizadas sobre o território urbano, mais especificamente em relação à configuração topográfica e suas relações com a drenagem das águas decorrentes da precipitação pluvial. Isso vem dificultar a instrumentalização de estudos sobre os escoamentos das águas e dificultar a compreensão espacial dos processos envolvidos e de grande importância para a constituição de sistemas mais eficientes de proteção contra as cheias nas cidades. Além disso, há a constatação (Tucci,1997) de que as cheias são um processo gerado principalmente pela falta de uma maior disciplina no processo de ocupação urbana. Obviamente que, a ausência de uma visão espacial das características do território urbano, enquanto bacia hidrográfica e, portanto, sistema de escoamento de águas pluviais, bem como sua interação sistêmica com a ocupação do território e sua evolução muito contribui para isso.

Em Pelotas, diante da necessidade de um Plano Diretor atualizado e da urgência para estabelecer as direções da expansão urbana, não existem definições claras quanto aos limites das áreas com risco de inundações. Expansões desregradas ocorrem aleatoriamente e ainda fazem parte da crescente lista de registros de ocupações irregulares no território urbano. Devido à cidade ter sido implantada em região de planície e bastante próxima a cursos d'água, há registros de cheias com prejuízos sociais consideráveis em 1941, 1977 e 1984 (ROTARY, 2001). Em função dos riscos de inundações, no período de 1940 a 1990 foi implementado pelo extinto Departamento Nacional de Obras e Saneamento (DNOS) o Sistema de Drenagem e Proteção contra as Enchentes de Pelotas. A implementação do sistema consistiu de um conjunto de obras baseadas em estudos realizados na década de 80 e decorrentes de vários projetos, dentre os quais destacam-se: PROJETO SANTA BÁRBARA (MAGNA, 1980) e PROJETO BARONEZA (MAGNA, 1978). Os projetos são baseados nas soluções clássicas de diques associados a áreas internas de "polders" e têm como propósito impedir a inundação da região urbana por água proveniente do canal São Gonçalo, que serve como ligação natural entre a Lagoa Mirim e a Lagoa dos Patos. Os diques possuem uma altura de 4,5 m, dos quais 4,0 m visam resguardar a população localizada nas áreas baixas da cidade. Este sistema, entretanto, protege apenas parte das ocupações urbanas e possui, como já mencionado, limite de proteção à cota de $4,0 \mathrm{~m}$, com um quebra ondas de 0,5 m. A Figura 1 representa o mapeamento existente desse sistema e cabe destacar que constituem os únicos mapas disponíveis que representam os dois projetos que compõe o mesmo. Ainda assim, demonstram parcialmente o território urbano e apresentam bastante imprecisão em relação aos limites das áreas representadas.

Na medida em que dados sobre relevo do conjunto do território são fundamentais para a compreensão da drenagem urbana, a ausência dos mesmos durante a realização de estudos e projetos compromete seriamente suas representações e a sua eficiência. A inexistência de análises básicas sobre a drenagem vinculada ao relevo urbano de Pelotas, bem como a precariedade das informações disponíveis, justificaram a realização dos estudos aqui apresentados.

A identificação prévia das áreas suscetíveis a inundações, através de simulações digitais, possibilita a elaboração de instrumento básico de apoio às decisões tomadas em relação ao uso e ocupação do solo, nas esferas pública e privada, evitando futuros problemas de calamidade devido às cheias, prevenindo desta forma e não apenas remediando os danos sociais, econômicos e ambientais que esses eventos causam. Sem essa identificação, medidas não-estruturais como zoneamento das áreas de risco com o devido mapeamento não podem ser adotadas, constituindo-se assim em grave problema para a gestão do espaço municipal devido à falta de instrumentos de apoio que permitam melhores avaliações sobre o território, bem como a definição de propostas de uso e ocupação do solo mais adequadas às características topográficas de cada área. 

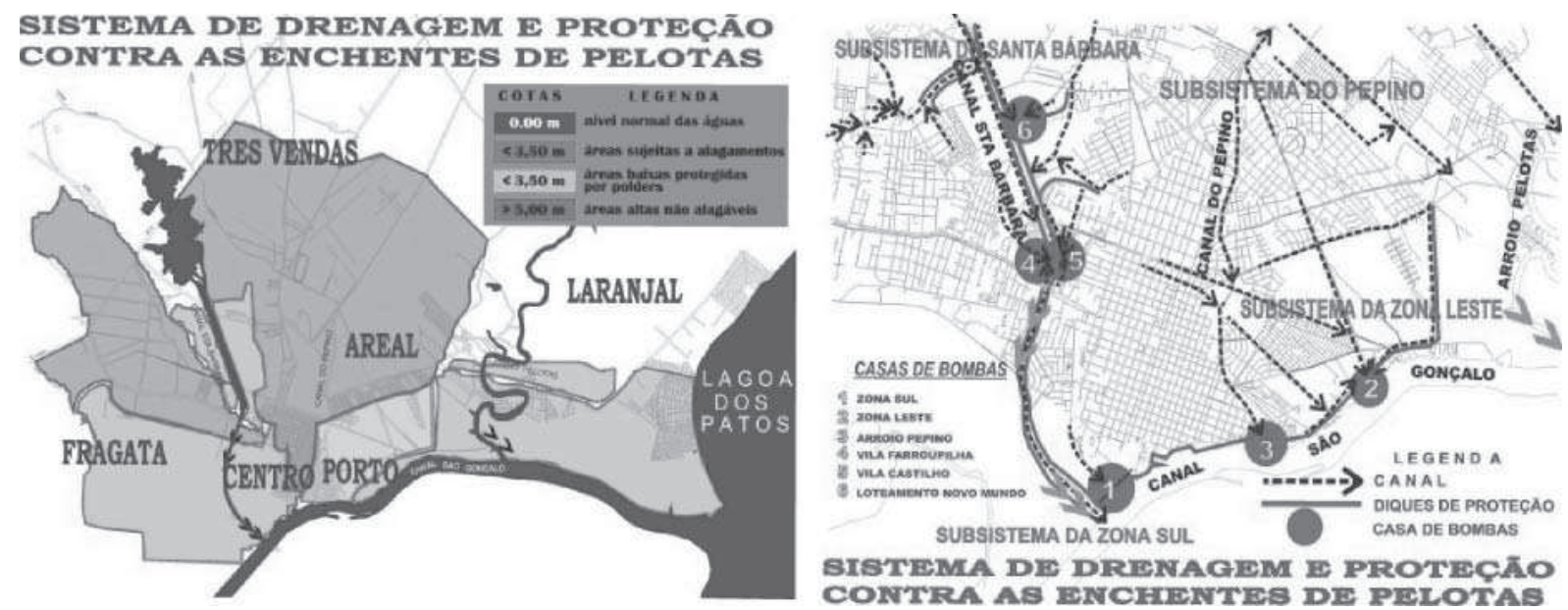

Figura 1: Mapas representativos do funcionamento do Sistema de Drenagem e Proteção contra Enchentes de Pelotas Fonte: SANEP/Pelotas, 2000

Com a utilização de recursos de geoprocessamento através da modelagem numérica de terreno, tornou-se possível, através do presente trabalho, demonstrar a viabilidade da aplicação de método próprio para identificação de áreas suscetíveis a inundações nas cidades e simulação de eventos de cheias em Pelotas, na forma de estudo de caso.

As informações geradas neste trabalho e estruturadas em um Sistema de Informações Geográficas (SIG) podem vir proporcionar o ponto de partida para a organização de uma base de referência de dados do próprio município que possibilitem o incremento de outras informações que, associadas a estas, poderão conduzir a diferenciadas avaliações e atualizações sobre o território urbano. Podem servir, portanto, como elemento de apoio a um Termo de Referência que traga subsídios para complementações futuras, em escalas variadas, e que permitam o encaminhamento de estudos mais detalhados.

\section{Base metodológica e instrumental utilizado para mapeamento das áreas inundáveis da cidade de Pelotas}

\section{Área de estudo}

Compreende a Zona Urbana da Figura 2, com limites definidos no II Plano Diretor de Pelotas (Lei Municipal 6525/80)

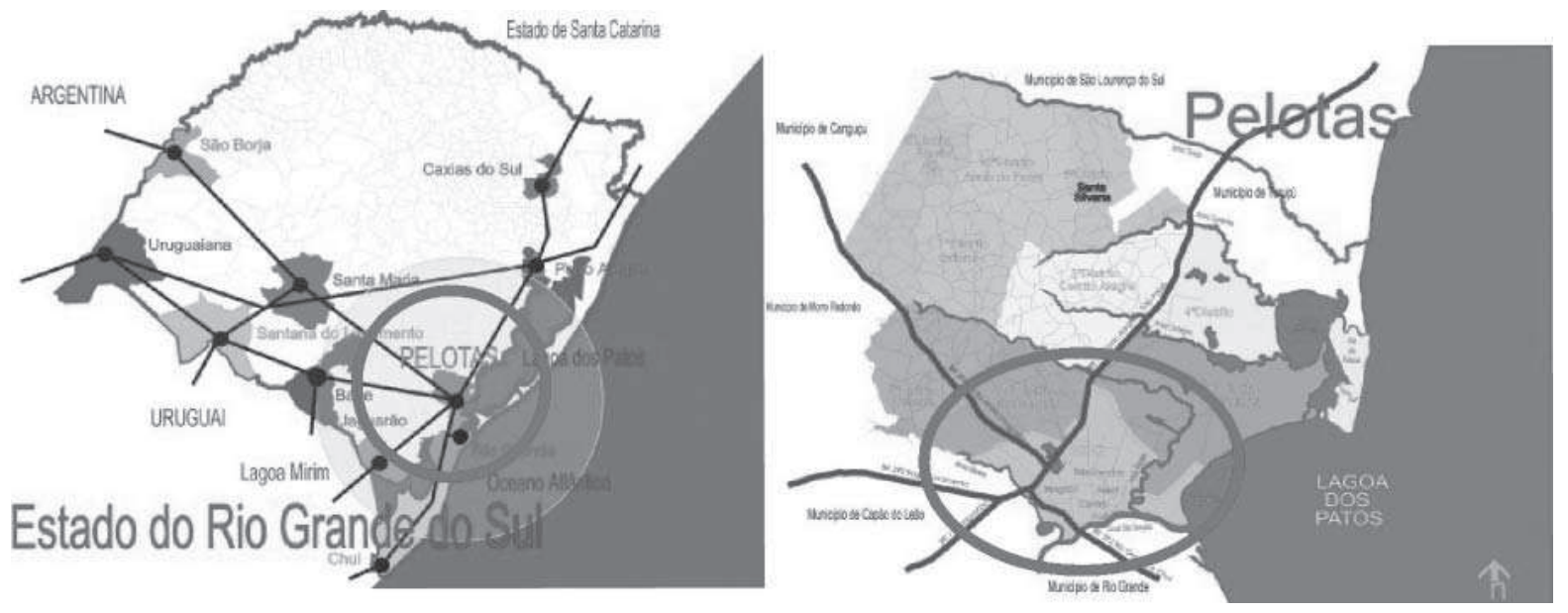

Figura 2: Mapa de localização de Pelotas no estado e zona urbana no município.

Fonte: Prefeitura de Pelotas, 2002 


\section{Método}

Através da aplicação de técnicas de Geoprocessamento, Sensoriamento Remoto e Gráfica Digital, foram realizados os processamentos necessários à confecção dos produtos gráficos parciais relatados a seguir, que posteriormente possibilitaram o cruzamento dos dados gerando os resultados finais.

O processamento dos dados para montagem dos mapeamentos foi realizado através de aplicativos especializados voltados para as áreas de geoprocessamento, sensoriamento remoto, edição de imagens, dentre outros. As tarefas realizadas foram:

a) Simulação digital do relevo do Município através de modelagem numérica, pela associação de curvas de nível (CN) e pontos cotados (PC), o que tornou possível identificar diferentes altitudes das áreas vindo compor o modelo numérico do terreno;

b) Geração de Imagem LSAT7-TM de outubro de 2001, Color com pixel 10m (R5G4B3) adquirida com a fusão da banda pancromática, o que permitiu o aumento da resolução para melhor visualização das áreas;

c) Georreferenciamento dos arquivos raster (matrizes) e vetores (linhas) com o propósito de realizar o cruzamento de dados diversos, por sobreposição, para diferentes análises;

d) Inserção dos dados em ambiente SIG, o que proporcionou a geração dos mapeamentos gráficos temáticos com informações possíveis de serem compartilhadas posteriormente.

\section{Resultados}

Tendo em vista a não existência de um modelo numérico de terreno (MNT) correspondente às áreas urbana e rural do município, envolvendo as bacias de drenagem para o local de estudo, foi necessária a construção do mesmo. Isso foi feito a partir da reunião de dois tipos de informações existentes: (i) curvas de nível (CN) e pontos cotados (PC), existente na Prefeitura de Pelotas, originados da restituição de levantamento aerofotogramétrico da zona urbana; (ii) de curvas de níveis de 20 em 20 m do município, originadas de cartas do Exército Brasileiro, digitalizadas e de posse do Serviço Autônomo de Saneamento de Pelotas (SANEP). Isso permitiu organizar, em um único conjunto de informações digitalizadas, o MNT completo do município, integrando áreas urbana e rural, para que visualizadas conjuntamente pudessem instrumentalizar o estudo das áreas de drenagem das bacias urbanas e rurais.

A simulação do relevo demonstrada na Figura 3, com cobertura de todo território do município representado no modelo digital já mencionado, possibilitou a construção de outras informações gráficas, como por exemplo as superfícies e canais de drenagem. Na figura visualiza-se o relevo das bacias e em vermelho o contorno do perímetro urbano, objeto dos impactos destacados pelo estudo, incorporados e agregados em um ambiente SIG (Sistema de Informações Geográficas).

A informação que caracteriza esses impactos se refere à identificação das áreas internas ao perímetro urbano suscetíveis à inundação. A partir do MNT foi possível simular a variação dos eventos de inundação, tomando por base a conformação do relevo e a análise de áreas inundadas com um nível das águas entre $1 \mathrm{~m}$ e $5 \mathrm{~m}$ (NMM Datum Torres - que é o referencial adotado para o canal São Gonçalo e Lagoa Mirim), como apresenta a Figura 4. O limite de 5 m representa a cota da planície de inundação da Bacia da Lagoa Mirim e é considerado neste estudo de caso como limite de risco. Através desta simulação, ficam evidenciadas quais áreas da zona urbana estão sujeitas ao alcance das águas.

Com os recursos alcançados através de técnicas de geoprocessamento e gráfica digital, pode-se visualizar sob forma de mapeamento a representação das áreas atingidas. Como está ilustrado na Figura 5, basicamente as áreas comprometidas estão situadas ao sul da zona urbana, na 
várzea do canal São Gonçalo. Essa área representa aproximadamente 37, 5\% do espaço urbano e atinge parcela considerável das ocupações de grandes bairros de Pelotas: Centro, Porto, Laranjal, Areal, Fragata e Três Vendas.
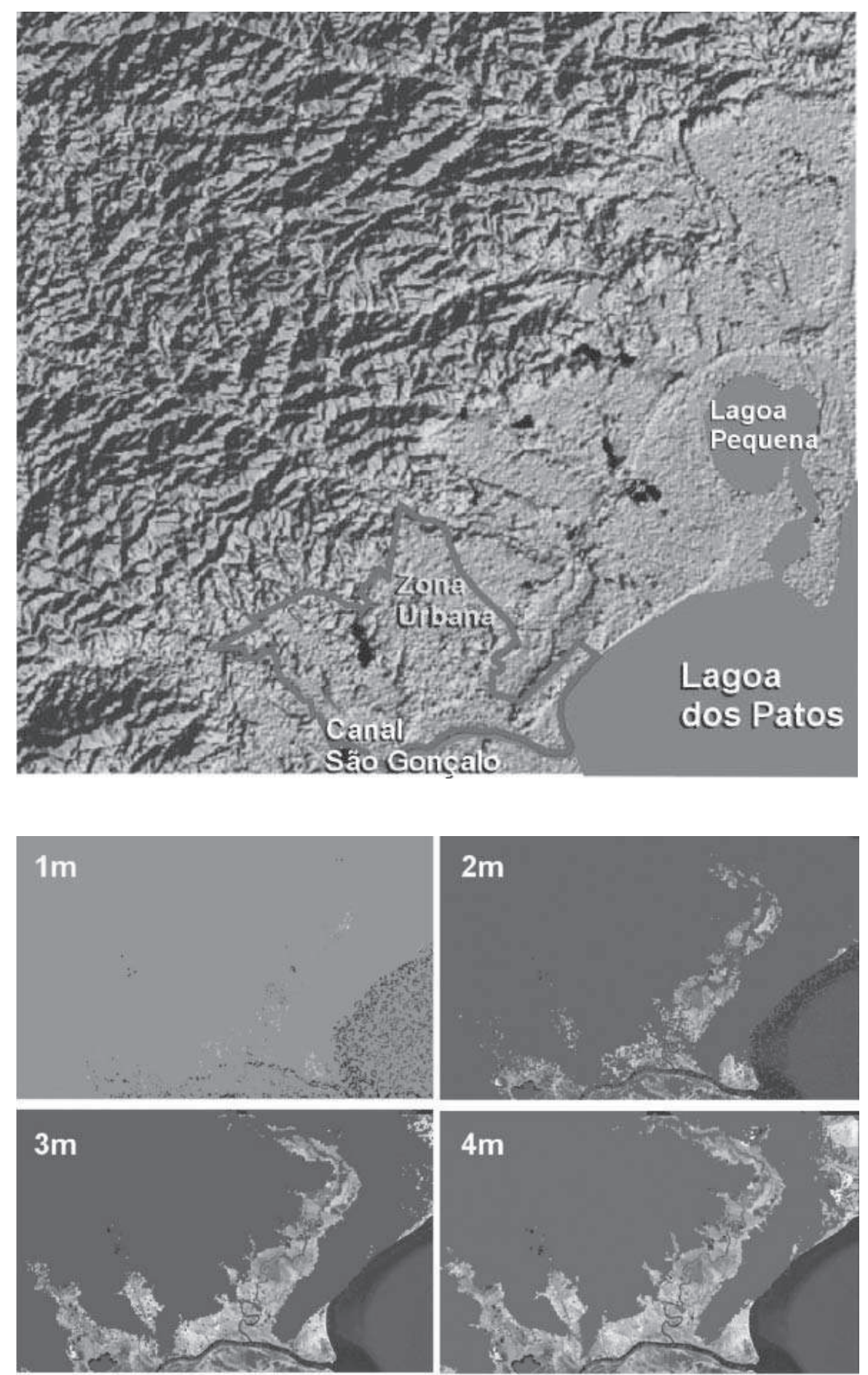
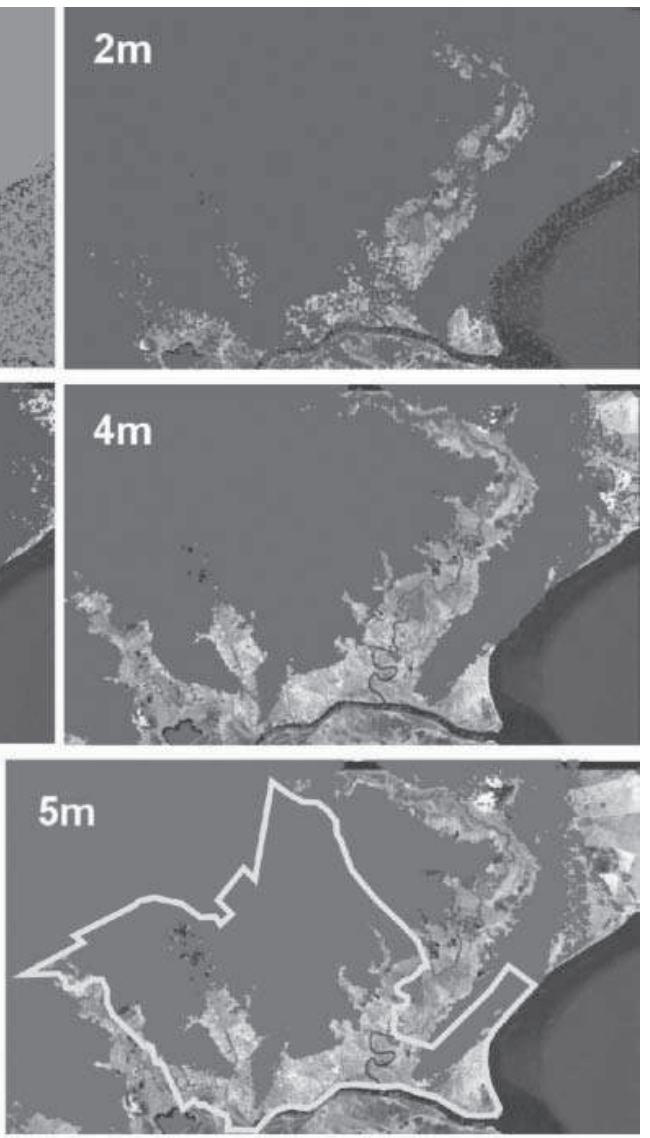

Figura 3: Vista de topo do relevo completo do território do município Fonte: SILVA, 2004

Figura 4: Simulação de eventos de inundação na área urbana, variando da cota $7 \mathrm{~m}$ até $5 \mathrm{~m}$, onde as áreas expostas representam as regiões atingidas Fonte: SILVA, 2004 


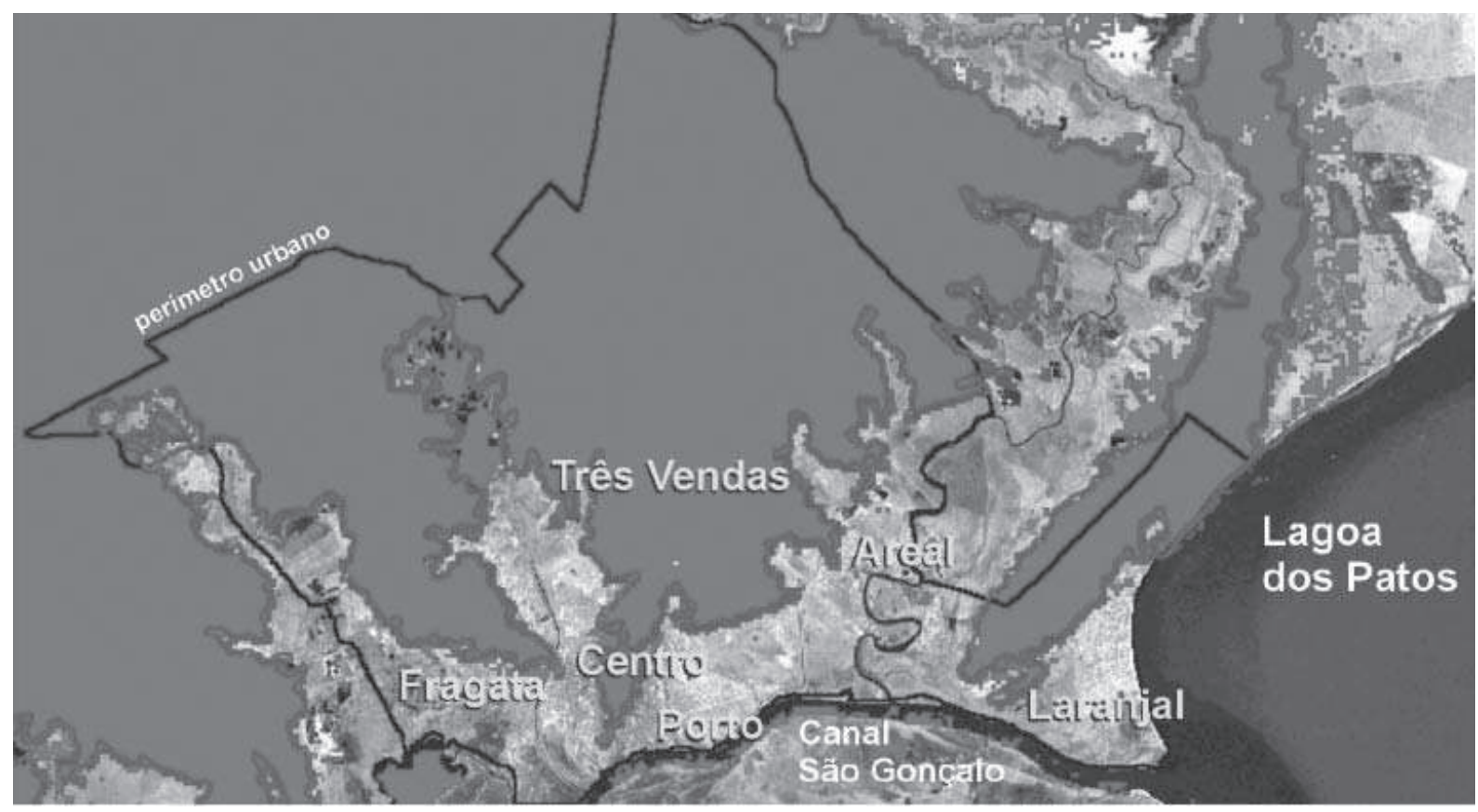

Figura 5: Representação das áreas atingidas até a cota $5 \mathrm{~m}$, potenciais áreas de risco da zona urbana de Pelotas Fonte: SILVA, 2004

Os resultados apresentados, estruturados em ambiente SIG, podem vir contribuir de forma significativa através de um melhor aproveitamento das informações existentes, trazendo uma maior precisão e agilidade dos processos que envolvam estudos sobre drenagem urbana. Isso vem, também, contribuir para o estudo e definições de áreas destinadas à expansão urbana, localização de equipamentos públicos e atividades polventes.

\section{Conclusões}

O material produzido poderá servir como mapeamento básico para estudos posteriores a serem realizados, visando melhor detalhar as informações existentes ou a serem levantadas, inclusive de forma setorizada.

A representação gráfica associada permitiu uma visão do conjunto do espaço urbano sobre o tema. Como aspectos fundamentais sobre a abordagem realizada, podem ser destacadas:

- a sistematização de mapas que órgãos públicos necessitavam e ainda não haviam sido elaborados;

- a constatação de que 37,5\% do território da zona urbana da cidade de Pelotas se encontram abaixo da cota de $5 \mathrm{~m}$ e, conseqüentemente, oferecem risco de inundação às ocupações nessas áreas;

- a visualização das áreas atingidas por inundação, através da representação gráfica, destacando as áreas de risco das ocupações ao Sul de Pelotas, da várzea do Canal São Gonçalo: Centro, Porto, Laranjal, Areal, Fragata e Três Vendas;

- a comprovação prática de que as simulações digitais possibilitam antecipar os eventos reais de inundação, permitindo identificar anteriormente as áreas a serem atingidas para a remoção prévia das populações nas situações de calamidade, bem como subsidiar a definição de políticas públicas que estabelecem diretrizes de ocupação e uso do solo.

Finalmente, o trabalho evidenciou a contribuição que o uso do ferramental de geoprocessamento e de manipulação de imagens pode trazer ao estudo de problemas como o da drenagem urba- 
na, no sentido de extrair preciosas informações de dados cartográficos e analíticos existentes, quando colocados de modo adequado em um ambiente SIG.

Essas informações, por sua vez, podem vir constituir um conhecimento relevante voltado para o apoio à tomada de decisões, cujos resultados podem vir impactar de forma decisiva a população de uma cidade ou município. Como exemplo, pode-se nesse sentido destacar o estudo e definições de áreas destinadas à expansão urbana, localização de equipamentos públicos e atividades polventes.

\section{Recomendações}

Com a constatação da falta de dados e informações consistidas e reunidas de forma sistêmica nos órgãos municipais, entende-se que, dificilmente, informações como essas apresentadas no presente trabalho seriam evidenciadas. Espera-se que o material produzido possa servir de referência para novos estudos nesse sentido.

Sendo assim, para a continuidade dos estudos recomenda-se:

- o melhoramento e manutenção das formas de representação das informações em novos estudos de aprofundamento sobre o tema, considerando que a informação visual é ferramenta importante ao suporte das informações analíticas;

- o georreferenciamento e confecção de mosaico das fotografias aéreas em baixa altitude da área urbana de Pelotas do ano de 2003, bem como do conjunto de imagens do Levantamento Aerofotogramétrico de 1995 (PREFEITURA, 1995), para realização de trabalhos que necessitem de melhor identificação e avaliação das áreas em escalas que permitam maiores detalhamentos, possibilitando assim análises da micro-drenagem urbana;

- dotar as Secretarias Municipais, responsáveis pelas diversas intervenções no território urbano, dos mapeamentos aqui apresentados, para melhor adequarem à drenagem urbana suas atividades e obras e suas diretrizes de uso e ocupação do solo, bem como para colocá-los em uso identificando as novas demandas para os estudos futuros sobre o assunto;

- identificar áreas para localização de equipamentos urbanos, aterros sanitários e próprias à expansão no que se refere ao risco de inundação;

- a estruturação de Sistema de Informações Geográficas - SIG para o município;

- a implementação conjunta de Sistema de Apoio à Decisão - SAD;

- intensificar e ampliar estudos sobre a drenagem relacionada a outros variados temas, proporcionando meios para viabilizar a construção de mapas temáticos, pois quanto maior e mais qualificados forem os estudos, melhor será a compreensão sobre as variáveis envolvidas ao tema da drenagem, aumentando as possibilidades de intervenções preventivas e minimizando assim elevados custos de correção das obras de drenagem e os grandes prejuízos decorrentes das inundações em Pelotas.

\section{Bibliografia}

DNOS. Sistema de Proteção contra Enchentes de Pelotas. Relatório do Departamento Nacional de Obras e Saneamento (DNOS). Pelotas: Departamento Nacional de Obras e Saneamento, 1987.

MOTA, Suetônio. Introdução à engenharia ambiental. Ed. ABES: Associação Brasileira de Engenharia Sanitária, 1998.

MOREIRA, Maurício Alves. Fundamentos do sensoriamento remoto e metodologias de aplicação. 2. ed. Viçosa: UFV, 2003. 
PREFEITURA DE PELOTAS. Levantamento aerofotogramétrico. Levantamento aerofotográfico e restituição digital da zona urbana. Pelotas: Prefeitura, 1995.

ROTARY CLUB PELOTAS NORTE. Saneamento básico na cidade de Pelotas: Situação atual e prioridades. Relatório de consultoria. Pelotas: Rotary Club Pelotas Norte, 2001.

TUCCl, Carlos E. M. Plano Diretor de Drenagem Urbana: Princípios e concepção. Revista Brasileira de Recursos Hídricos, Associação Brasileira de Recursos Hídricos, vol. 2, n. 2, p. 5-12, 1997. Disponível em: <http://www.abrh.org. br.> 